\title{
The assessment of mental capacity
}

\author{
Matthew Hotopf
}

Matthew Hotopf
PhD MRCPsych,
Professor of
General Hospital
Psychiatry, King's
College London

Clin Med

2005;5:580-4
ABSTRACT - Mental capacity is required for an adult to make autonomous treatment choices. This review highlights recent legal and clinical developments in the field. The recent English Mental Capacity Act 2005 is described and compared with mental health legislation. Some of the difficulties of defining mental capacity are then outlined. Recent research regarding mental capacity in general hospital patients is summarised. Such research indicates firstly that capacity can reliably be assessed; secondly, that among general hospital inpatients, approximately one-third may lack capacity; and thirdly, that mental incapacity in this setting is mainly driven by cognitive impairment caused by delirium or dementia. This is contrasted with psychiatric inpatients, where the problem is no more frequent, but mainly relates to psychotic illness. The article finishes with some general guidance as to how to assess mental capacity in the general hospital.

KEY WORDS: assessment, delirium, dementia, law and medicine, mental capacity, mental disorders, mental health law

For a patient to make an informed treatment decision he or she must have sufficient information, be able to make the decision free from coercion, and have mental capacity. Mental capacity can be affected by a number of conditions, such as dementia and delirium, learning disability, and psychiatric disorder. According to the English Mental Capacity Act $2005,{ }^{1}$ a patient lacks capacity if because of 'an impairment of, or a disturbance in the functioning of, the brain or mind' (which can be permanent or temporary) he or she is unable to:

(a) understand information relevant to the decision

(b) retain that information

(c) use or weigh the information, or

(d) communicate a decision.

In this article I shall discuss the law in more detail before describing the assessment of mental capacity, the frequency of patients lacking capacity in various clinical situations and risk factors or associations of mental incapacity. I shall conclude with some recommendations on the assessment of patients lacking capacity in clinical practice.

\section{The law in England and Wales}

The Mental Capacity Act 2005 has a number of explicit principles. Firstly, people are assumed to have capacity. Secondly, before deciding that someone lacks capacity to make a decision, all steps must be taken to enhance his or her decision-making abilities. Thirdly, someone cannot be said to lack capacity simply because he or she is making an unwise decision. Fourthly, the person's best interests should always be taken into account in making a decision on his or her behalf; and finally, the least restrictive treatment option should always be used. The Mental Capacity Act, and guidance in the common law which preceded it, ${ }^{2,3}$ make it very clear that mental capacity is functional, ie situation specific. This means that it would be incorrect to state that a patient with dementia is unable to make any decision related to his or her care. The patient's capacity must be assessed for each decision he or she confronts.

One of the main innovations of the Mental Capacity Act has been to allow proxy decisionmakers. Prior to this legislation, under common law, no other person could consent to treatment on an adult patient's behalf. The new law allows two main mechanisms for this to happen. The first allows a person who still has mental capacity to donate a lasting power of attorney to one or more people. The lasting power of attorney is similar to the enduring power of attorney which preceded it, but now allows for the donor's care (including medical care) to be decided upon by the donee. (The 'donor' is the individual giving power of attorney, and the 'donee' is the person who has been given power of attorney.) The second provision is that the court can now appoint a deputy (or deputies) who can make decisions on the behalf of a person who already lacks capacity. Whilst these two forms of proxy may become increasingly common, it is likely that the majority of patients lacking capacity will have no such provision, and will be treated as previously by doctors making decisions.

The Mental Capacity Act places great emphasis upon decisions being made in the patient's best interests. Everyone making decisions on the patient's behalf (be it the court or its appointed deputy, the donee of a lasting power of attorney, or a clinician) is expected to use a best interests test. The Act states that the patient should be encouraged to participate as far 
as possible in decision-making. In determining best interests, the duty of the decision-maker is to determine as far as possible what the patient's likely preferences would have been, and to consult other people involved in the patient's care - such as close relatives and donees of lasting power of attorney or appointed deputies of the court. Legal weight is given to advance decisions, where a person is able to refuse certain treatments in the future, provided the decision is made when the person has capacity. However, there are limits on the scope of advance decisions in the case of life-sustaining treatments. The Act is clear about the use of restraint in treating patients, and states that this is only lawful if the patient is thought to be at risk of harm and the restraint is proportionate to the seriousness and risk of harm. However, restraint can be used if it is necessary to sustain the patient's life, or prevent a serious deterioration in his or her condition.

\section{Mental health law}

There has been considerable controversy about the differences inherent in mental capacity legislation compared with mental health law, with a new Mental Health Bill ${ }^{4}$ before Parliament. Essentially these differences stem from the two strands of legislation having different purposes, even though their effect - treatment of vulnerable people without their consent - may be similar. Mental capacity legislation has to a large extent been developed to deal with the needs of people with cognitive difficulties - either due to learning disability or dementia. Mental health law has developed to serve the needs of people with mental disorders in mind, as well as the needs of society, which in some circumstances needs to be protected from perceived danger caused by such disorders, and it has been argued that the current proposed legislation places too much emphasis on public safety, and too little on patients' rights. ${ }^{5}$ Mental health law adopts a status approach to decision-making, in other words, once a patient is 'sectioned' and treated formally under the English Mental Health Act $1983,{ }^{6}$ the clinical team does not need to consider his or her capacity to make any individual decision. Following from this, there is no specific test of best interests, and advance decisions carry no legal weight. This, it is argued, is discriminatory, ${ }^{7,8}$ and in some - predominantly North American - jurisdictions, capacity-based mental health legislation has been developed.

\section{Alternative definitions of mental capacity}

One difficulty of researching mental capacity is that it is a legal, clinical, ethical and social construct, and definitions vary according to jurisdictions. This might suggest that it would be difficult to apply consistent definitions. One approach, developed particularly by Thomas Grisso and Paul Appelbaum in a series of influential studies funded by the US MacArthur Foundation, ${ }^{9-11}$ has been to identify a number of underlying constructs derived from legal rulings in US case law. Four dimensions relating to mental capacity have resulted: understanding, appreciation, reasoning and expressing a choice. These can be assessed using the MacArthur Competence Assessment Tool - Treatment (MacCAT-T). ${ }^{12}$
Grisso and Appelbaum's formulation of mental capacity places more emphasis on appreciation than does English legislation. They define mental capacity thus: ${ }^{9}$

Competent decision making according to the appreciation standard requires recognition that one is suffering from a disorder and that the generally accepted risks and benefits of treatment apply to one's own situation...failures in appreciation often are considered to be core components of major psychiatric disorder.

There is a wide range of interpretation of appreciation, particularly as one moves away from overt psychotic symptoms towards the influence of emotional disorders, affect, and even culturally held beliefs. ${ }^{13}$ Although it is true that appreciation may be subsumed under the third criterion of the Mental Capacity Act definition (use of and ability to weigh information), the definition appears less elastic than Grisso and Appelbaum's. This difficulty is explored in more depth below when considering the impact of powerful emotions on mental capacity.

Another controversy in the assessment of mental capacity is the threshold at which a judgement that someone lacks capacity is set. Clearly the underlying constructs on which mental capacity assessments are based are dimensions. What degree of lack of understanding or appreciation or poor reasoning is required to deem someone as lacking capacity? One legal solution has been to set the threshold according to the severity of the consequences of the decision. Therefore, if the decision has very serious consequences, for example leading to the almost certain death of the patient, the clinician making the capacity assessment needs to be more confident that the patient has capacity than if the consequence of treatment refusal were trivial. It has been argued that such an approach is ethically unsatisfactory ${ }^{14-16}$ and essentially paternalistic. Others have argued persuasively that it is not so much the threshold which should be changed, but that the assessor must be satisfied that the margin of error in making the capacity assessment is as small as possible when the decision has grave consequences. ${ }^{17}$ In practice what this means is that the person assessing mental capacity needs to perform a more thorough assessment if the consequences of the decision are serious. From a clinical perspective it seems both inevitable and desirable that the riskier the decision made by a patient, the more searching will be the assessment of mental capacity.

\section{Can capacity be assessed in a valid and reliable manner?}

It is difficult to determine whether capacity assessments have criterion validity - the only 'gold standard' is the decision of a court of law. Provided capacity assessments measure what they purport to measure they can be said to have face validity; and if they correlate with measures of cognitive impairment and psychopathology, they also can be considered to have predictive validity. However, given some of the difficulties in applying the definition of mental capacity described above, can two individuals assessing mental capacity do so in a reasonably reliable manner? 
The answer to this question depends on whether the two assessors are performing a similar assessment on similar criteria, or whether a researcher using an interview is pitted against a clinician. When the same measures are being used, the reliability achieved can be very high indeed. In a recent systematic review, ${ }^{18}$ we identified 12 studies in which a binary (yes/no) decision was made as to whether patients had mental capacity, and found that the median kappa value in these studies was 0.79 . The kappa coefficient is a measure of agreement which takes chance agreement into account, and takes a value of -1 to 1 , with 1 indicating perfect agreement. A value of 0.79 indicates very substantial inter-rater reliability, indeed higher than that reported for what may seem more 'objective' investigations such as interpreting mammograms, or the results of exercise ECGs. ${ }^{19}$

However, when researchers performing a detailed assessment are pitted against clinicians simply asked for their views as to whether the patient is able to make a specific treatment decision, the results are less encouraging - we identified eight studies with this design, with a median kappa value of 0.40 , indicating only moderate agreement. The other main finding was that clinicians identified far fewer patients as lacking capacity than did the researchers.

These findings suggest that despite its complex definition, capacity can be reliably assessed provided the person performing the assessment has explicit guidelines. Clinicians' apparent under-recognition of mental incapacity may indicate that they are working from the legally correct perspective that patients are presumed to have capacity.

\section{What proportion of patients lack mental capacity?}

Of course the frequency of mental incapacity depends upon the setting and nature of the sample. Some of the original MacArthur studies used medical and psychiatric patients, and found that among medical outpatients with coronary heart disease, mental incapacity was fairly infrequent $(12 \%) .{ }^{20}$ Studies of medical inpatients show a different picture. The largest was performed by the author and colleagues in King's College Hospital. ${ }^{21}$ One hundred and fifty-nine patients were interviewed, all of whom had been admitted acutely on general medical take. The patient was asked about the main treatment or investigation for which they were hospitalised, using the MacCAT-T. ${ }^{12}$ We found that $31 \%$ of all patients interviewed were judged according to English legal standards to lack mental capacity. We also found that only one-quarter of the patients we recognised to lack capacity were identified as such by their treating clinical teams. Similar studies in general hospitals have found rates of mental incapacity ranging from 9 to $52 \% .^{22-24}$

Moving to psychiatric inpatient settings, the results are remarkably similar. In an equivalent study among inpatients in the Maudsley Hospital, we found $44 \%$ of a consecutive sample of patients admitted acutely to psychiatric wards lacked capacity. ${ }^{25}$ The use of the Mental Health Act was (unsurprisingly) strongly associated with lack of mental capacity, but the two did not overlap completely. Thus there are a significant number (around 10\%) of people who have mental capacity but are detained under the Mental Health Act. Those campaigning for capacity-based mental health law consider this group to be discriminated against in the current and proposed legal solution. There is also a group of patients (approximately 18\% of those lacking capacity) ${ }^{26}$ who lack mental capacity but are admitted apparently compliantly. This group falls into what has been termed the 'Bournewood Gap'. This refers to a recent ruling by the European Court where the 'informal' admission to a psychiatric ward of a patient lacking mental capacity was ruled unlawful, a ruling whose repercussions are yet to be felt in British clinical practice.

A final group of patients - those who are seen in accident \& emergency (A\&E) departments and have taken overdoses - are relevant to hospital medicine. Only one study has addressed this group, and found that when initial capacity assessments were performed, over $60 \%$ of patients lacked capacity to consent to treatment of their overdoses. However, the study also reassessed patients having provided written information (and time), and found that in many, mental capacity had returned. ${ }^{27}$ Such relatively swift improvement with additional information should remind us that the law insists on the clinician doing as much as possible to enhance decision-making capacity before acting on the basis that someone lacks it. Unfortunately, this measured approach conflicts with UK government targets which place A\&E departments under great pressure to discharge patients quickly. ${ }^{28}$

Does it matter if a high proportion of patients treated by physicians lack capacity, but the physician fails to recognise the problem? Most of the patients in our general hospital sample were happy to accept treatment despite not fully understanding its purpose, and presumably trusted the medical team to deliver appropriate care. And the legal presumption that people have capacity may also have influenced the low 'recognition' of incapacity. It is not at all clear that recognising these problems would lead to better care, but there are certain circumstances when important irreversible decisions are to be made, where it seems prudent to consider the patient's capacity. Such decisions might include serious procedures, discharge from hospital to a nursing home, and decisions around end-of-life care such as 'do not resuscitate' orders.

\section{Risk factors for lack of mental capacity}

Research which has looked for risk factors associated with lack of mental capacity has drawn largely unsurprising findings. Risk factors vary according to setting: in general medical settings capacity is mainly driven by cognitive impairment, ${ }^{21}$ whereas in psychiatry it is driven by the nature and extent of psychopathology, in particular that related to psychotic and manic illness. ${ }^{25}$ Further, patients who refuse treatment in a psychiatric setting are particularly likely to be judged lacking capacity, indicating a central role of insight in capacity. One study has shown that impaired capacity in patients with psychotic illness may be driven by problems in metacognition. ${ }^{29}$ Metacognition refers to the assessment an individual makes of his or her performance on a cognitive task. It seems that poor performance per se is a 
less important risk factor than failing to recognise that one is performing poorly.

Reassuringly, given the subjective nature of capacity assessments, most research does not find strong associations between loss of mental capacity and socio-demographic variables. In particular, no clear associations have been described with gender, ethnicity, educational status or social class. Advancing age is associated with loss of capacity, certainly for medical inpatients, and this is not fully explained by an increased prevalence of cognitive impairment.

\section{The assessment of capacity in clinical practice}

It is not uncommon for liaison psychiatrists to be asked to assess mental capacity in general medical patients. ${ }^{30}$ Although all registered medical practitioners should be able to assess capacity, it is reasonable to gain a second opinion, particularly if the decision has significant consequences, or if the impairments causing mental incapacity are difficult to define.

The first task in assessing mental capacity is to define the exact decision which the patient has to make, and to identify what the likely outcomes are for the various possible courses of action. It is rarely the case that a patient faces a single decision - for example, a person with an infected diabetic foot may have to decide either to have no treatment; to have palliative treatment; to have a (further) course of intravenous antibiotics; to undergo local debridement; or to have a more extensive amputation. The clinical team needs to have a reasonably clear idea of the likely benefits and risks associated with each course of action, and in many situations the evidence may be too weak to be able to do this. It is then essential to ensure that the patient has been given this information. Where there are language barriers, interpreters should be used. When there are other forms of communication difficulties, such as deafness, sign language or other methods should be used.

Usually the issue of mental capacity arises for two main reasons. Either the clinical team is aware that the patient has difficulties in making a decision, due to cognitive impairment or severe mental illness; or a patient makes what is apparently a rash decision, refusing treatment which the clinical team believes is indicated. In the first set of circumstances the main priority is to establish the nature and extent of any disorder and to determine whether it is likely to interfere with decision-making abilities in the ways described in the Mental Capacity Act. Patients refusing treatment may ultimately need a similar assessment, but the clinician needs to be wary of jumping to the conclusion that just because the patient is refusing treatment, it necessarily indicates he or she has a problem with mental capacity. The Mental Capacity Act is clear that people have the right to make what others would consider to be unwise choices. Further, treatment refusal often comes about due to a breakdown in relationships between the patient and clinical team, with the patient often complaining of poor or confused communication, and often feeling demoralised about his or her medical condition. Under these circumstances a formal mental capacity assessment (which may involve referral to a psychiatrist) may be counter-produc- tive. Instead measures need to be taken to identify and address the grounds of the patient's complaints.

The assessment should then determine whether any disorder might interfere with decision-making processes. In medical patients, the most common causes of impaired decision-making are unconsciousness and cognitive impairment usually caused by dementia, delirium or a combination of the two. It is often more difficult to determine whether mental disorders such as schizophrenia or depression impair decision-making capacity. In patients with schizophrenia, problems often arise due to cognitive disorganisation such as thought disorder, and 'negative' symptoms such as poverty of speech and thought. These impairments typically have a general impact on decision-making, akin to those caused by cognitive impairments. In other circumstances, delusions may impact on decision-making through a more specific mechanism - for example, a belief that the doctor imparting the information is part of a plot to harm the patient. Whilst the patient is able in other respects to understand and retain the information imparted, he or she is unable to weigh such information. In patients with depression, decision-making can be impaired due cognitive slowing and in severe cases pseudodementia. It can also be impaired due to distorted cognitions which in extreme forms may border on delusions - such as feelings of unworthiness or guilt, again affecting the patient's ability to use and weigh information effectively.

Capacity can also be impaired by less well defined problems. In A\&E departments, a familiar problem is the patient who has self harmed and refuses life-saving treatment such as acetylcysteine infusions for paracetamol overdose. Such patients may be admitted and restrained under the Mental Health Act, but treatment of their physical condition comes under mental capacity legislation. Such patients may not have a well defined mental disorder, but have personality difficulties, and are reacting to current stressful events in a way which appears dysfunctional. Any impairment of mental capacity is likely to be driven by powerful emotions, but it is unclear whether this amounts to 'an impairment of, or a disturbance in the functioning of, the brain or mind' as specified in the Mental Capacity Act.

Having made a decision that a person lacks mental capacity, it is then necessary to assess his or her best interests, which will depend upon previously expressed views, the views of family members and others who have cared for the person, and views that the person is currently expressing. If the person has a temporary impairment of capacity, say due to delirium, the decision should be delayed if possible until capacity has returned. Every effort should be made to enhance capacity - for a patient with delirium, it may be possible to find a lucid interval. For a patient with depression, the mood may have lifted by the evening.

Decisions regarding mental capacity and best interests should be carefully documented. If in doubt, it is wise to request a second opinion; to consult other professionals (such as the GP or social worker) who know the patient well; to refer the case to the trust's legal department; and to consult one's defence organisation. In many cases there is no 'right' answer, but a careful and well documented assessment will go a long way in protecting both the patient and doctor. 


\section{References}

1 Mental Capacity Act 2005.

2 Lord Chancellor. Making decisions: the Government's proposals for making decisions on behalf of mentally incapacitated adults. London: The Stationery Office, 1999.

3 Lord Chancellor's Department. Who decides? London: The Stationery Office, 1997.

4 Draft Mental Health Bill, Cm 6305-1, Department of Health, 2004.

5 House of Lords and House of Commons Joint Committee on the Draft Mental Health Bill. Draft Mental Health Bill, 2005. Report No: HL Paper 79-1

6 The Mental Health Act 1983. London: HMSO, 1983.

7 Szmukler G, Holloway F. Mental health legislation is now a harmful anachronism. Psychiatr Bull 1998;22:662-5.

8 Szmukler G, Holloway F. Reform of the Mental Health Act. Health or safety? Br J Psychiatry 2000;177:196-200.

9 Appelbaum PS, Grisso T. The MacArthur Treatment Competence Study. I: Mental illness and competence to consent to treatment. Law Hum Behav 1995;19(2):105-26.

10 Grisso T, Applebaum PS. The MacArthur treatment competence study III: Abilities of patients to consent to psychiatric and medical treatments. Law Hum Behav 1995;19(2):149-74.

11 Grisso T, Appelbaum PS, Mulvey EP, Fletcher K. The MacArthur Treatment Competence Study: II. Measures of abilities related to competence to consent to treatment. Law Hum Behav 1995;19(2):127-48.

12 Grisso T, Applebaum PS, Hill-Fotouhi C. The MacCAT-T: A clinical tool to assess patients' capacities to make treatment decisions. Psychiatr Services 1997;48(11):1415-19.

13 Glass KC. Refining definitions and devising instruments: two decades of assessing mental incompetence. Int J Law Psychiatry 1997;20(1):5-33.

14 Wicclair MR. Patient decision-making capacity and risk. Bioethics 1991;5(2):91-104.

15 Cale GS. Risk-related standards of competence. Bioethics 1999;13(2): $131-53$.

16 Demarco JP. Competence and paternalism. Bioethics 2002;16(3): 231-45.

17 Buchanan A. Mental capacity, legal competence and consent to treatment. J R Soc Med 2004;97:415-20.

18 Hotopf M, Okai D, Owen G, Singh S, Churchill R. Mental capacity: a systematic review of empirical research. London: Department of Health, 2005.

19 Sackett DL, Haynes RB, Guyatt GH, Tugwell P. Clinical epidemiology: a basic science for clinical medicine, 2nd edn. Boston: Little Brown, 1991.

20 Grisso T, Appelbaum PS. Comparison of standards for assessing patients' capacities to make treatment decisions. Am J Psychiatry 1995; 152(7):1033-7.

21 Raymont V, Bingley W, Buchanan A, David AS et al. Prevalence of mental incapacity in medical in-patients and associated risk factors: cross-sectional study. Lancet 2004;364:1421-7.

22 Etchells E, Katz MR, Shuchman M, Wong G et al. Accuracy of clinical impressions and Mini-Mental State Exam scores for assessing capacity to consent to major medical treatment. Comparison with criterionstandard psychiatric assessments. Psychosomatics 1997;38(3):239-45.

23 Holzer JC, Gansler DA, Moczynski NP, Folstein MF. Cognitive functions in the informed consent evaluation process: a pilot study. J Am Acad Psychiatry Law 1997;25(4):531-40.

24 Kitamura F, Tomoda A, Tsukada K, Tanaka M et al. Method for assessment of competency to consent in the mentally ill: Rationale, development, and comparison with the medically ill. Int J Law Psychiatry 1998;21(3):223-44.

25 Cairns R, Maddock C, Buchanan A, David AS, Hayward P et al. Prevalence and predictors of mental incapacity in psychiatric inpatients. Br J Psychiatry 2005;187:379-85.

26 Bellhouse J, Holland AJ, Clare ICH, Gunn M, Watson P. Capacity-based mental health legislation and its impact on clinical practice: 1) admission to hospital. J Mental Health Law 2003;9-23.
27 Jacob R, Clare ICH, Holland AJ, Maimaris C et al. Self harm, capacity, and refusal of treatment: implications for emergency medical practice. A prospective observational study. Emergency Med J (in press).

28 Henderson M, Hicks A, Hotopf M. Reforming emergency care. Psychiatr Bull 2004;28(1):23.

29 Koren D, Poyurovsky M, Seidman LJ, Goldsmith M et al. The neuropsychological basis of competence to consent in first-episode schizophrenia: a pilot metacognitive study. Biol Psychiatry 2005;57: 609-16.

30 Ranjith G, Hotopf M. 'Refusing treatment - please see'. An analysis of capacity assessments carried out by a liaison psychiatry service. J $R$ Soc Med 2004;97:480-2. 